\title{
A Study on Misconception of Using Brackets in Arithmetic Expression
}

\author{
Kaushik Das \\ Assistant Professor, Department of Mathematics \\ Gobardanga Hindu College, Gobardanga, West Bengal, India
}

\section{OPEN ACCESS}

Manuscript ID:

EDU-2020-08043252

Volume: 8

Issue: 4

Month: September

Year: 2020

P-ISSN: 2320-2653

E-ISSN: 2582-1334

Received: 15.06 .2020

Accepted: 20.07.2020

Published: 01.09.2020

Citation:

Das, Kaushik. "A Study on Misconception of Using Brackets in Arithmetic Expression." Shanlax International Journal of Education, vol. 8, no. 4, 2020, pp. $76-80$.

DOI:

https://doi.org/10.34293/ education.v8i4.3252

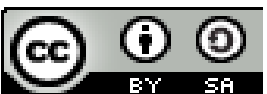

This work is licensed under a Creative Commons Attribution-ShareAlike 4.0 International License

\begin{abstract}
The present study focused on the lack of knowledge of the double use of brackets in arithmetic expressions and the difficulty in the operatively of expression for mathematics application at the school level. Learning the other rules and formulas of mathematics involves learning the use of a bracket. Binding is useful in both arithmetic and algebra. If the bracket is not used properly, the value of the mathematical result is completely changed. The concept of this bracket is inserted into the students while learning school-based mathematics. So at the beginning of the bracket learning process, school-based textbooks, curriculum, and teachers are of great importance. The methodology of the proposed study is based on the document-based analysis. This study employed including studying international and national journals, library consultation, expert opinion, online journals, periodical, newspapers, and documents. Finally, the researcher suggested the importance, precaution, and effectiveness of using brackets in arithmetic.
\end{abstract}

Keywords: Arithmetic and algebra, Arithmetic expressions, Misconception of using brackets, School-mathematics and Use of Bracket.

\section{Introduction}

In India, mathematics is widely believed to be the most difficult subject in the curriculum, and it is identified as the main reason for secondary school, not ending the academic year of the school. School education in India includes the following levels of schools: Elementary: Grades 1-5; Intermediate or Higher Elementary: Grades 6-8, Secondary: 9-10 Levels and Higher Secondary: Grades 11-12. The provision of school education is mainly the sole responsibility of the State Government, subject to the broad rules of the Central Government. Responsibility of Mathematics Teachers to finds out the problems and challenges to integration Mathematics and Pedagogical knowledge in the teaching-learning of mathematics class. Most of the students learned from the textbooks published and assigned by the state or central government. The arithmetic method makes the condition of some word problems unnecessary. Adequate mathematical fluency is necessary, but not sufficient, a prerequisite for being able to solve complex mathematical problems. Better Mathematics Teaching is dependent upon the integration of knowledge and communication technologies (ICT) into the teaching and learning of mathematics in Teacher- Training College and School level. Also, Teacher-Educators' job satisfaction depends upon their Gender, Marital Status, Educational Qualification, and Age, experience, income status, and professional development. It is important for teachers who are working in a school. Competition for basic mathematical calculations is essential in many areas of present and future life for students. To overcome this shortage of teachers in this country, we need to provide more and better reading material and provide regular reprinted textbooks of mathematics. Students should read in-depth about mathematics. They need to internalize the mathematical vocabulary so that they can apply ideas instead of just mimicking a process. 
Students with learning disabilities are especially at risk for various serious math problems. Students' incorrect understanding of quality can be noted when students commonly work out a string of unequal problems such as $3 \times(14+36)$ as $14+36=50 \times 3=$ 150 (Stacey and McGregor, 1997). Students struggle to solve a problem such as $4+5=[$ ] +6 abstractly, they often have few problems modeling the correct answer using manipulatives.

\section{Objectives of the Study}

1. To find out misconceptions about using bracket in Arithmetic.

2. To find out the error computation of mathematics problem- solving by using a bracket.

3. To find out the Misconceptions of students thinking about mathematics.

\section{Statement of the Problem}

This study was aimed at misconception arithmetic use of brackets at the secondary level. This is an area that has been researched; however, there are certain facts that research has not attended yet. As a result, the researcher believes that it is important to investigate and identify factors influencing students' attitudes towards mathematics subjects' knowledge for using the bracket concept. The present study was structured to investigate from each student the most important school \& College-related determinants of likely and disliking mathematical applications. The particular value of the present study is that it should identify and categorize different perceptions and outcomes of different students.

\section{Methodology of the Study}

This study employs an interpretative approach where qualitative data were collected and analyzed by the document study of the research papers from journals, reports, books, edited books, and online documents. The methodology of the proposed study is based on the document-based analysis.

\section{Methodology Employed}

- It is based on qualitative research.

- It has the chief characteristics of recent documentbased analytical research.

\section{Research Materials}

- Government documents,

- Peer-reviewed Journals

- Books,

- Magazines,

- On-line documents from some relevant and reliable internet sources.

\section{Data Collection Process}

Multiple procedures have been employed, including studying international and national journals, library consultation, online journals, expert opinion, periodical, newspapers, and documents.

\section{Data Analysis}

Historical and sociological approaches have also been adopted for analyzing the collected data. No statistical analysis has been furnished.

\section{Results \& Discussions \\ The Teacher's Role}

Most experts believe that young children have sufficient informal knowledge about mathematics. The role of the teacher is to create a relationship between their ability to use informal math and the ability to understand more formal math found in grade school. Teachers must know that kids can help explain what they already know so that they can "innovate" in math for themselves. A reflective teacher helps the child discover and communicate ideas that did not happen spontaneously without the help of an adult. The math-teacher in the classroom, with his vocabulary, needs to explain traditional numerical problem-solving quizzes, lesson assignments, and problems that students will use in the processes they use and math problems. The math teacher will inform you of the use of single and brackets to solve mathematical problems. Give appropriate examples and conduct practical tests if necessary. At higher levels, the concepts of mathematics become more abstract. At this point, the comprehension of mathematics goes beyond the ability to identify relevant information in a word problem or to use the correct mathematical operation. To understand mathematics at this high level, students need to be able to describe concepts, classifications, and concepts related to the problem 
of textbook words, which may or may not fit well. Students can learn the use of mathematics during practice teaching, which includes a two-year course in teacher training. To reach this level of understanding, students need the ability to read about concepts at an abstract level. A working vocabulary is important to this. The practical aspect of the preservice and in-service teachers' subjective qualities with applications depends on the knowledge of the teacher educators who are training them during their training period. Also, special skills are needed to understand the operations used in mathematics and the marks of brackets.

\section{Use of Brackets in Arithmetic Expression}

Students are often unaware that brackets can be used as symbols for grouping terms and as multiplier operators in an additive situation. To illustrate this, the researcher took an example. If this equality is shown to students, then there are two different solutions. Is this equality true or false?

$$
21-(8-9)=(21-8)-9 \text {. }
$$

On the first side of this equality, the bracket indicates the grouping of 8-9. Moreover, the same bracket expresses a multiplication by -1 , denoted by the minus sign which precedes it: - (8-9). The operatively is carried out with whole numbers. However, on the second side of the previous equality, the operations are effected in the domain of natural numbers, and the brackets indicate only the grouping of 21-8.

Again, different identities are available from students in solving algebraic inequalities. The students do not understand expressions such as the following:

$$
\begin{aligned}
& (a-b)+(p-c)=(a+p)-(b+c) \\
& (a-1)^{2}=\left(a^{2}-2 a\right)+1
\end{aligned}
$$

From (1), the left-hand side the bracket group terms, and on the right-hand side, the bracket is used as a multiplicative operator (observe the minus sign in front of the second bracket). Again, from (2), we see that the left-hand side the brackets indicate squaring an expression. On the right-hand side, the brackets group the first two terms of a trinomial. It is very important to warn the student from the very beginning, that is, from the education of arithmetic, what numbers they have been working on in practice.
Even after deciding the sequence of steps, students repeat only the same kind of activity: expanding bracket, dealing with positive and negative signs, collecting like terms, and so on. Students must be able to solve multiple involved equations step by step. Mathematicians need to be able to maintain a series of arguments without error. However, there was a tendency to include this moderately complex equation by spending higher complexity problems in textbooks, where students must plan a path through sub-problems to reach the target. Several books included investigations, which would be classified as a high-complexity problem. Without investigation, it is divided into several explicitly mentioned subproblems, each of which usually becomes a separate issue of low complexity.

\section{Conclusions}

In this article, the researcher indicates the conceptual and operative problems which arise during the process of teaching-learning of using the bracket. On the other hand, expressions such as (1) and (2) above are analyzed as propositional rules lacked visual salience. The process of adding and subtracting terms like intelligibility is a solid foundation for understanding and understanding the early stages of learning algebra and arithmetic. At the same time, the use of brackets must be learned properly. This process requires an explicit understanding.

\section{Recommendations}

The conclusions of the research described in this article suggest the following recommendations:

- Informing students about the numerical domain to be addressed, explaining the use of brackets twice.

- I was using the method of teaching mathematics through diagnosis, which can detect errors and false ideas about a topic. Subsequently, mathematics produced a design for learning that highlighted the difficulties and solved through discussion.

- To encourage the use of teaching models with whole numbers, different from the model of the number line, which permits other interpretations of the negative number, different from that of 
positions or displacements.

- To establish a Mathematics Laboratory.

- To promote active learning for mathematics subjects.

- To relate mathematics in real-life situations.

\section{Future Research}

As a researcher, my journey will not end with this work. Several issues came up during this expedition. I hope to explore this fascinating arena further. I will extend the ideas that emanated from this research into other mathematics learning domain.

\section{References}

Casey, Julie. "The Effects of Five Minute Practice, Unlimited Practice, with SAFMED Cards on Correct and Error Rate in Math Facts for Two Elementary School Children with Learning Disabilities." International Journal of Special Education, vol. 18, no. 1, 2003, pp. 66-73.

Das, Kaushik, and Ratna Chowdhury. "Analytical Study on Practice Teaching of B.Ed. Students in B.Ed. Department, Gobardanga Hindu College, under WBSU in India." International Journal of Scientific Research and Reviews, vol. 8, no. 2, 2019, pp. 3882-3898.

Das, Kaushik, et al. "Applications of Mathematical Knowledge in History, Geography, Fine-Arts \& Physical Education Subjects in Two-Year B.Ed. Programme: Indian Context." Journal of Emerging Technology and Innovative Research, vol. 6, no. 6, 2019, pp. 8-15.

Das, Kaushik, et al. "SWOT Analysis of Teacher Educators in B.Ed. Department under West Bengal State University in West Bengal, India." Research Review International Journal of Multidisciplinary, vol. 4, no. 6, 2019, pp. 87-91.

Das, Kaushik. "Job Satisfaction among Educators According to their Socio-Economic Status in the Government Aided and Private B.Ed. Colleges in West Bengal." Shanlax International Journal of Arts, Science and Humanities, vol. 7, no. 2, 2019, pp. 11-16.
Das, Kaushik. "Lack of Mathematical Knowledge in two-year B.Ed. Programme: Indian Context." Research Journal of Educational Sciences, vol. 7, no. 3, 2019, pp. 1-6.

Das, Kaushik. "Pedagogical Approaches in Mathematics: Indian Perspectives and Practices." International Journal of All Research Writings, vol. 1, no. 3, 2019, pp. 16-21.

Das, Kaushik. "Role of ICT for Better Mathematics Teaching." Shanlax International Journal of Education, vol. 7, no. 4, 2019, pp. 19-28.

Falkner, Karen, et al. "Children's Understanding of Equality: A Foundation for Algebra." Teaching Children Mathematics, vol. 6, no. 4, 1999, pp. 232-236.

Gallardo, Aurora. "Negative Numbers in the Teaching of Arithmetic Repercussions in Elementary Algebra." Seventeenth Annual Meeting for the Psychology of Mathematics Education, 1995.

Ginsberg, H.P. "Toby's Math." The Nature of Mathematical Thinking, edited by Sternberg, Robert J., and Talia Ben-Zeev, Routledge, 1996, pp. 175-202.

Goldman, Susan, et al. "Extended Practice of Basic Addition Facts: Strategy Changes in Learning Disabled Students." Cognition and Instruction, vol. 5, no. 3, 1988, pp. 223-265.

Haring, Norris G., et al. The Fourth R: Research in the Classroom, Merrill, 1978.

Kirshner, David, and Thomas Awtry. "Visual Salience of Algebraic Transformations." Journal for Research in Mathematics Education, vol. 35, no. 4, 2004, pp. 224-257.

MacGregor, Mollie, and Kaye Stacey. "Students' Understanding of Algebraic Notation: 11-15." Educational Studies in Mathematics, vol. 33, 1997, pp. 1-19.

National Centre for Educational Research and Training (2006). Position paper of the National Focus Group on the Teaching of Mathematics. Retrieved from www.ncert. nic.in/html/pdf/school curriculum/position papers/math.pdf. 
Paul, Raja, and Kaushik Das. "Integration of 2019, pp. 223-232.

Mathematics Teaching Concept through Fine

Vygotsky, L.S. Mind in Society: The development Arts of Two Year B.Ed. Programme in West Bengal: An Overview." Innovative Pedagogy of Higher Psychological Processes, Harvard and Effective Teaching, Blossom books, University Press, 1978.

\section{Authors Details}

Kaushik Das, Assistant Professor, Department of Mathematics, Gobardanga Hindu College, Gobardanga, West Bengal, India, Email ID: kaushik.das53@gmail.com 